\title{
Desigualdades, interdependências e afrodescendentes na América Latina
}

Sergio Costa

Tradução de Otacílio Nunes

As desigualdades sociais têm sido pesquisadas convencionalmente como processos sincrônicos no quadro das fronteiras nacionais e articuladas pelo conceito de classe. Isso significa que a investigação estabelecida não considerou adequadamente as dimensões históricas e os entrelaçamentos globais ou as interconexões entre classe e outras classificações sociais que moldam as desigualdades existentes.

Algumas contribuições recentes tentam corrigir essas deficiências analíticas a partir de diferentes perspectivas. Com o objetivo de superar o nacionalismo metodológico, um primeiro grupo de contribuições vem se concentrando em articulações de estruturas de desigualdades nacionais e globais, mostrando como as desigualdades correspondem a entrelaçamentos entre os processos sociais em diferentes níveis geográficos: local, nacional, global.

Um segundo grupo de contribuições investiga a relação entre diferentes eixos de estratificação, concentrando-se em como as desigualdades sociais surgem nas intersecções entre diferentes adscrições, particularmente raça, classe, gênero e etnia.

Este artigo apresenta um breve balanço dos debates em ambos os campos, bem como um conjunto de recursos para superar as atuais deficiências da pesquisa sobre desigualdades interdependentes. A fim de ilustrar como alguns desses recursos operaram analiticamente, a segunda metade do artigo 
discute o caso das desigualdades sociais que afetam os afrodescendentes na América Latina.

Desigualdades sociais e interdependência

Os níveis de avanço da pesquisa latino-americana sobre interdependências entre desigualdades observadas em diferentes regiōes do mundo e sobre as relações entre diferentes eixos de estratificação social são bastante diferenciados. Na verdade, enquanto a pesquisa sobre as interdependências entre as distintas categorizações sociais ao longo das últimas décadas levou a um acúmulo de descobertas importantes, a pesquisa sobre entrelaçamentos entre estruturas de desigualdade em diferentes regiōes do mundo é menos desenvolvida. Esse campo tem um importante precursor na teoria da dependência (cf. Cardoso e Falleto, 1969). Desde a década de 1980, no entanto, a pesquisa sobre desigualdade na América Latina foi cada vez mais dominada por abordagens econométricas que serviram para direcionar o foco analítico para uma perspectiva centrada no Estado-nação.

Na próxima seção, apresento um panorama de ambas as áreas de pesquisa buscando contemplar seus estados variados de avanço: assim, as observações sobre as interdependências entre os diversos eixos de estratificação se concentrarão na discussão na e sobre a América Latina. As interdependências entre diferentes regiōes, no entanto, são situadas em um contexto internacional mais amplo.

Eixos de estratificação: classe, raça, gênero e etnia

$\mathrm{Na}$ América Latina, a pesquisa sobre as inter-relações entre raça/etnicidade e classe tem sido realizada pelo menos desde a década de 1930. As obras de sociólogos norte-americanos sobre relações raciais no Brasil são, aqui, particularmente dignas de nota. O primeiro estudo sistemático pode ser creditado à tese de doutorado de Donald Pierson, acadêmico da Escola de Chicago, que realizou sua pesquisa de campo em Salvador, Bahia, entre 1935 e 1937. Pierson (1942) concluiu que as desigualdades por ele observadas poderiam ser mais bem entendidas a partir da categoria de classe. A questão da discriminação racial é tratada por ele como questão acessória, isto é, como uma "deformação" individual sem maior relevância sociológica.

Tendo em vista a importância menor atribuída à discriminação racial, o estudo de Pierson se volta para as diferenças entre casta e classe. Ele estava 
interessado principalmente em demonstrar que as desigualdades sociais no Brasil não são reproduzidas por um rígido sistema de castas baseado na cor, mas que o país tinha conseguido estabelecer uma sociedade de classes multirracial em que a mobilidade social ascendente era possível, apesar das adscriçōes racistas.

Anos depois, Wagley (1952, pp. 148ss.) corroborou as conclusões de Pierson em relação ao desaparecimento de castas raciais, mas não sem acrescentar a seguinte observação: "Com raras exceções, as pessoas da classe alta do Brasil são caucasianas na aparência física [...]. O critério de raça torna-se muitíssimo decisivo na determinação da posição social".

Marvis Harris (1956) desenvolveu esse ponto de vista, concluindo que em sua região de pesquisa, Minas Velhas, também localizada na Bahia, as supostas habilidades e os talentos da população em estudo poderiam ser situados em uma escala de acordo com a categoria de "cor da pele": quanto "mais branco" um indivíduo era categorizado, maior a probabilidade de habilidades e talentos positivos serem atribuídos a ele. Harris faz duas constataçôes fundamentais.

Em primeiro lugar, ele descobriu que as categorias de racialização associadas à cor deviam ser colocadas em uma escala gradual, em vez de constituírem dois polos binários entre grupos de brancos e negros classificados de acordo com a ascendência. Para Harris, uma escala gradual como essa tinha enorme importância, uma vez que definia características fenotípicas de maneira tal que não só os brancos, mas também os negros, podiam usar a escala para afirmar superioridade sobre outros que eram categorizados como mais escuros. Em segundo lugar, Harris refere-se à falta de uma sobreposição simples e imediata das categorias de raça e classe. Ou seja, apesar da importância dos traços físicos para a construção de adscrições sociais, e, portanto, para definir a posição social de um indivíduo ou grupo, esse aspecto concorre com outros fatores. Ainda que as características físicas nunca sejam totalmente neutralizadas na escala, elas recebem mais ou menos peso dependendo da situação de um determinado indivíduo em relação aos outros fatores que são relevantes nas classificaçōes existentes:

Não há papel de status para o negro como negro, nem para o branco como branco, exceto na cultura ideal. A raça é apenas um de vários critérios, os quais determinarão como a massa de outros indivíduos realmente se comportará em relação a ele. Em outras palavras, riqueza, ocupação e educação, os outros três grandes princípios de classificação, têm até certo ponto o poder de definir a raça. É devido a esse fato que 
* A data entre colchetes refere-se à edição original da obra. Ela é indicada na primeira vez que a obra é citada. Nas demais, indica-se somente a edição utilizada pelo autor [N.E.].

1. O grupo de pesquisa da Universidade de São Paulo reunido em torno do sociólogo Florestan Fernandes, que incluía os entāo doutorandos Fernando Henrique Cardoso e Octávio Ianni, chega também a resultados que evidenciam a influência das adscriçōes raciais sobre as diferenças sociais (cf. Cardoso, 1962; Cardoso e Ianni, 1960; Ianni, 1966). A própria pesquisa de Florestan Fernandes em São Paulo (cf. Bastide e Fernandes, 1959; Fernandes, 1965) também demonstrou a importância de atitudes racistas para explicar a desigualdade social no Brasil (cf. também Guimarães, 2002). não há nenhum grupo socialmente importante em Minas Velhas que seja determinado por características puramente físicas (Harris, 1956, p. 126).

Em seu estudo comparativo sobre o Brasil e os Estados Unidos, Degler $\left([1971]^{*} 1976\right.$, pp. 232ss.) concorda com a afirmação de Harris de que ter "pele negra" representa tanto uma barreira para a mobilidade social ascendente quanto um motivo de segregação social. De acordo com Degler, o que distinguia o Brasil dos Estados Unidos nesse momento era o que ele chamava de "válvula de escape do mulato". Ele acreditava que a presença de "mulatos" tidos como "socialmente aceitáveis" borrava a "fronteira de cor". Nesse aspecto, e ao contrário do que ocorria nos Estados Unidos, a grande presença social de "mulatos" complicava a ideia de uma "raça branca" e uma "raça negra" como um atributo abrangente que ofusca todas as outras características. Contudo, esse aspecto não impedia nem o avanço nem a circulação contínua de ideias e práticas racistas ${ }^{1}$.

Desde a década de 1980, novas gerações de cientistas sociais norte-americanos e estudiosos brasileiros formados nos Estados Unidos têm examinado as relações entre brancos e negros no Brasil, concentrando-se principalmente na categoria de raça. Essa perspectiva teórica e metodológica, conhecida como "estudos raciais", representa atualmente o paradigma de pesquisa hegemônico de estudos sociológicos sobre o racismo no Brasil (cf. Hanchard, 1994; Telles, 2003).

Dentro desse quadro, o uso da categoria raça como recurso analítico é legitimado por meio de observações de desigualdades sociais, fundamentadas em atribuições racistas. Baseando seu trabalho em indicadores sociais, representantes do campo de estudos raciais enfatizam que as desigualdades raciais no Brasil seguem padrões birraciais comparáveis a categorizações usadas nos Estados Unidos. De acordo com essa visão, a mobilidade social é estruturada, efetivamente, em torno de uma hierarquia bipolar, apesar da realidade de muitas cores de pele diferentes que moldam a percepção que um indivíduo tem de si mesmo e de seu entorno (cf. Costa, 2006, 2010a).

Para os fins deste artigo, duas importantes distinções devem ser feitas entre o primeiro conjunto de estudos realizados por pesquisadores norte-americanos até a década de 1970 e um segundo conjunto realizado desde a década de 1980, quando os estudos raciais se tornaram o paradigma dominante. $\mathrm{Na}$ verdade, cientistas sociais como Pierson e Harris falavam de relaçóes raciais. No entanto, esse aspecto estava vinculado ao exame de diferentes formas de relações de grupo (étnicas, culturais, inter-religiosas, e assim por diante). 
Os estudos raciais, em contraste, definem a polaridade entre branco e negro como central, perdendo de vista, assim, as etnicidades - ou seja, os complexos processos de significação social e performatização das características corporais - como um elemento que molda desigualdades sociais.

Todavia, os estudos raciais incorporaram as discussōes sobre interseccionalidade, um debate que começou nos Estados Unidos no final da década de 1980. Como consequência, os autores no campo dos estudos raciais incluíram as adscriçôes de gênero ao lado da discriminação racial, como fator determinante das desigualdades sociais (cf. Lovell, 1995; Nobles, 2000). As investigações realizadas antes da década de 1980 ignoravam em grande parte essa dimensão.

Para o exame das interdependências entre os diferentes eixos de estratificação na América Latina, e sobretudo na região dos Andes, o conceito de "desigualdades horizontais" é igualmente relevante. Esse termo foi cunhado pela economista do desenvolvimento Frances Stewart (cf. Stewart, 2000, 2010; Stewart, Brown e Mancini, 2005). De acordo com Stewart, a posição social de um indivíduo em uma dada sociedade corresponde à soma das desigualdades verticais e horizontais. As primeiras referem-se às diferenças entre os indivíduos numa escala social, e as últimas, às diferenças entre grupos.

Ao se concentrar nas desigualdades horizontais, Stewart tem como objetivo ampliar a visão economicista convencional sobre as causas da desigualdade social. Ela vê a identidade de grupo ou a pertença a um grupo como determinadas não só por fatores econômicos, mas também por critérios políticos, religiosos, étnicos, raciais e específicos de gênero. No entanto, a questão da definição de grupo não é fácil de ser respondida. Isto é, se um indivíduo pode sentir-se pertencente a grupos diferentes ao mesmo tempo, como se define um grupo? Além disso, considerando que as próprias desigualdades geram sentido de pertença a grupos, a relação causal entre pertencimento a um grupo e desigualdade não é de forma alguma óbvia. Assim, Stewart e seus colaboradores argumentam que:

Até certo ponto, os limites do grupo se tornam endógenos à desigualdade entre grupos. Se as pessoas sofrem discriminação (isto é, experimentam desigualdade horizontal), elas podem então se sentir mais fortemente identificadas culturalmente [com o grupo discriminado], em particular se outros as categorizam em grupos com o propósito expresso de exercer discriminação (assim criando ou impondo DIs [desigualdades horizontais]) (Stewart, Brown e Mancini, 2005, p. 9). 
Para contornar as dificuldades na definição de grupos relevantes, Stewart propõe testar a influência de diferentes categorizações sociais sobre as desigualdades sociais. Aqui devem ser consideradas também as autoatribuições de pertença a um determinado grupo.

Em conformidade com a abordagem das desigualdades horizontais, Thorp e Paredes (2010) examinaram as desigualdades sociais no Peru e identificaram três grupos principais: brancos, mestizos e indígenas. Em combinação com outros eixos importantes de desigualdade - em particular local de residência (rural, urbana etc.), gênero e classe -, o pertencimento de um indivíduo a um desses três grupos determina sua posição na sociedade peruana. Isso é ilustrado pelos dados sobre pobreza mostrados na Tabela 1.

TABELA 1

Status de pobreza no Peru, 2008, em porcentagem (de acordo com o gasto domiciliar per capita).

\begin{tabular}{l|l|l|l}
\hline \hline & INDíGENAS & Mestizos & BRANCOS \\
\hline \hline Extremamente pobres & 24,1 & 5,8 & 1,8 \\
Pobres & 29,3 & 22,2 & 7,2 \\
Não pobres & 44,6 & 72,0 & 91,0 \\
\hline
\end{tabular}

Fonte: Thorp e Paredes (2010).

Global, transnacional, transregional: desigualdades e entrelaçamentos

Entre os esforços recentes para superar o nacionalismo metodológico na pesquisa sobre desigualdade, duas abordagens podem ser destacadas: a abordagem do sistema-mundo e a abordagem transnacional.

Partindo da teoria da dependência e das primeiras obras de Immanuel Wallerstein, a abordagem do sistema-mundo concentra-se nas interdependências entre diferentes regiōes, bem como no caráter histórico das desigualdades. O trabalho recente de Moran e Korzeniewicz (cf. Korzeniewicz e Moran, 2009; Korzeniewicz e Moran, 2008; Korzeniewicz, 2011) representa um exemplo paradigmático dos desenvolvimentos dos estudos de desigualdade, partindo da ótica do sistema-mundo.

Esses autores distinguem, quanto à distribuição de renda, dois grandes blocos de países: um primeiro grupo caracterizado por uma grande disparidade na distribuição de renda e um segundo grupo que mostra apenas pequenas disparidades de renda. Seus estudos mostram que a posição dos países incluídos em cada um desses dois grupos, via de regra, não mudou desde o século XVIII. Fica claro, então, que esses padrões de desigualdade remontam ao período colonial. Em contraste com a literatura até agora he- 
gemônica, os autores demonstram que a persistência de níveis baixos e altos de desigualdade não pode ser explicada só por fatores internos. Em vez disso, o potencial de um país para remediar a desigualdade existente por meio de políticas redistributivas está indissociavelmente ligado à economia global e à política mundial. Portanto, a posição de um país na economia mundial e suas desigualdades internas são conectadas de modo interdependente:

Os argumentos que apresentamos exigem uma perspectiva alternativa sobre estratificação. Em vez de serem nacionalmente limitados, [...] os arranjos institucionais constituem mecanismos relacionais de regulação, operando dentro dos países e ao mesmo tempo moldando interações e fluxos entre eles (Korzeniewicz e Moran, 2008, p. 11).

A posição dos atores sociais nas estruturas transnacionais de desigualdades, e não as formaçôes históricas de desigualdade, é o foco central das abordagens transnacionais na pesquisa sobre desigualdade. Eu gostaria de me referir brevemente à pesquisa de dois sociólogos alemães, Ludger Pries e Anja Weiß, como exemplares dessa abordagem. Ambos trabalham com desigualdade e migração transnacional.

O trabalho empírico de Pries (2008) está voltado principalmente para a migração de trabalhadores entre o México e os Estados Unidos. Ele argumenta que a unidade tradicional de referência na pesquisa sobre desigualdade, ou seja, as fronteiras do Estado-nação, não é por si só suficiente para explicar como trabalhadores migrantes são incorporados em estruturas de desigualdade. De fato, a mobilidade social potencial desses migrantes é determinada não apenas dentro do México ou dos Estados Unidos, mas se desloca simultaneamente entre diferentes mercados de trabalho nacionais. De acordo com Pries, esses migrantes se movem entre novos espaços transnacionais, plurilocais, onde novas formas de cidadania e acesso a direitos são praticadas e também ocorrem mudanças nas condições materiais de vida por meio de remessas e intercâmbio de informações. Assim, torna-se indispensável que a pesquisa sobre desigualdade leve a sério os espaços plurilocais/transnacionais:

Paralelamente a essas unidades de análise (local, nacional, supranacional e global) - encaixadas como bonecas russas -, o plurilocal como unidade de análise para fenômenos como a economia doméstica ou estratégias de educação é de fundamental importância, como no caso de migrantes transnacionais e do espaço social distribuído por diferentes sociedades nacionais (Pries, 2008, p. 62). 
2. Ver http://www.desiguaLdades.net.

3. O foco em desigualdades entrelaçadas é inspirado por Conrad e Randeria (2002), que cunharam a expressão "modernidades entrelaçadas" para superar tanto interpretações eurocêntricas da história moderna quanto o conceito de modernidades múltiplas. De modo semelhante ao que fazem Conrad e Randeria, insistimos nas interdependências entre estruturas de desigualdades observadas em diferentes regiōes do mundo. Indo além do foco de pesquisa deles, usamos o conceito de desigualdades entrelaçadas também para descrever interdependências entre diferentes eixos de estratificação social (classe, raça, gênero etc.).
O trabalho de Anja Weiß (Weiß, 2005; Berger e Weiß, 2008) concentra-se em migrantes qualificados na Alemanha. Diferentemente de Pries, ela não está à procura de uma unidade espacial de referência que ajude a explicar novas biografias transnacionais. $\mathrm{O}$ que ela busca são categorias para descrever a posição social de atores além das fronteiras nacionais. Baseando sua análise no conceito de capital de Bourdieu, ela mostra como certos grupos de migrantes detêm capital cultural válido transnacionalmente, de modo que sua posição na sociedade que os recebe é determinada em parte por esse capital acumulado. Em outros casos, feitos que gozam de elevada valorização no país de origem (por exemplo, obter o diploma de uma universidade de elite na Índia) não são reconhecidos no novo país de residência:

Argumentei que a autonomia geográfica, social e estrutural em relação ao Estado-nação pode ser um aspecto importante da mobilidade social ascendente no mundo. Um curso de vida migratório pode ser caracterizado por autonomia social. E pode ser definido estruturalmente como um portfólio de recursos que são reconhecidos e solicitados mundialmente. Um subgrupo específico de migrantes altamente qualificados combina em certa medida ambas as características. Como seu capital cultural é aceito e solicitado transnacionalmente, as barreiras à migração são reduzidas, o que lhes permite deslocar-se com poucas restrições em mercados de trabalho globalizados. A maioria dos migrantes está em uma posição menos desejável. A migração resulta em uma depreciação do seu capital que só tem valor num local específico. Não obstante, os migrantes são capazes de melhorar sua posição social com a mudança espacial (Weiß, 2005, p. 723).

\section{Articulação de categorizações sociais e interdependências históricas e geográficas}

Até este ponto, focalizei em separado abordagens de pesquisa que examinam interdependências entre desigualdades sociais e diversas categorizações sociais (classe, raça, gênero, etnia etc.), por um lado, e os vínculos entre processos transnacionais e desigualdades sociais, por outro. A Research Network on Interdependent Inequalities in Latin America, sediada em Berlim² $^{2}$ está trabalhando na integração de ambas as formas de interdependência por meio da construção de uma abordagem designada como "desigualdades entrelaçadas" 3 . O Quadro 1 apresenta as dimensões que essa abordagem incorpora. 
QUADRO 1

Desigualdades sociais e interdependências: novas abordagens

\begin{tabular}{|c|c|c|c|c|c|}
\hline $\begin{array}{l}\text { ABORDAGEM/ } \\
\text { AUTOR }\end{array}$ & $\begin{array}{l}\text { Desigualdades hori- } \\
\text { zontais (por exem- } \\
\text { plo, Stewart) }\end{array}$ & $\begin{array}{l}\text { Estudos raciais } \\
\text { (por exemplo, Tel- } \\
\text { les, Nobles) }\end{array}$ & $\begin{array}{l}\text { Abordagem do sis- } \\
\text { tema-mundo (por } \\
\text { exemplo, Moran, } \\
\text { Korzeniewicz) }\end{array}$ & $\begin{array}{l}\text { Abordagem transna- } \\
\text { cional (por exemplo, } \\
\text { Pries, Weiß) }\end{array}$ & $\begin{array}{l}\text { Desigualdades entre- } \\
\text { laçadas }\end{array}$ \\
\hline $\begin{array}{l}\text { UNIDADE DE } \\
\text { ANÁLISE }\end{array}$ & Local, nacional & Nacional & $\begin{array}{l}\text { Regiōes mundiais: } \\
\text { centro, periferia, } \\
\text { semiperiferia }\end{array}$ & $\begin{array}{l}\text { Espaços transnacio- } \\
\text { nais/plurilocais }\end{array}$ & $\begin{array}{l}\text { Contextos relacionais: } \\
\text { regimes e configura- } \\
\text { ções de desigualdade }\end{array}$ \\
\hline Foco & $\begin{array}{l}\text { Assimetrias eco- } \\
\text { nômicas, políticas, } \\
\text { legais }\end{array}$ & $\begin{array}{l}\text { Dominação racial/ } \\
\text { de gênero }\end{array}$ & $\begin{array}{l}\text { Fluxos: comércio } \\
\text { global, fluxos finan- } \\
\text { ceiros }\end{array}$ & $\begin{array}{l}\text { Atores: classes trans- } \\
\text { nacionais, famílias, } \\
\text { redes de migrantes }\end{array}$ & $\begin{array}{l}\text { Fluxos e atores trans- } \\
\text { regionais; assimetrias } \\
\text { econômicas, políticas, } \\
\text { legais }\end{array}$ \\
\hline $\begin{array}{l}\text { EIXOS DE } \\
\text { DESIGUALDADE }\end{array}$ & $\begin{array}{l}\text { Grupos definidos por } \\
\text { nacionalidade, raça, } \\
\text { religião etc. }\end{array}$ & Classe, raça, gênero & Classe & $\begin{array}{l}\text { Classe, nacionali- } \\
\text { dade }\end{array}$ & $\begin{array}{l}\text { Interdependências en- } \\
\text { tre diversos eixos de } \\
\text { desigualdade }\end{array}$ \\
\hline Temporalidade & Sincrônica & Sincrônica & Diacrônica & Sincrônica & Sincrônica/diacrônica \\
\hline
\end{tabular}

Fonte: Elaboração própria a partir de Pries (2008).

Como se torna evidente aqui, desigualdades entrelaçadas como produto de interdependências entre diferentes regiōes, bem como entre diversas categorizações sociais, não podem ser estudadas a partir de uma unidade de análise espacial predefinida. Em vez disso, são necessárias unidades relacionais capazes de incorporar os diversos fatores (relevantes) que contribuem para conformar as estruturas de desigualdade. Essas unidades relacionais devem variar dependendo do respectivo objeto de investigação. Em certos casos, o conceito de regime de desigualdade vem se revelando particularmente útil para explorar as desigualdades entrelaçadas existentes.De acordo com minha própria definição, um regime de desigualdade ${ }^{4}$ inclui:

- Lógica de estratificação/redistribuição definida como estática (sociedades de castas), dinâmica (sociedades de classe) ou combinada (classe com atribuição racial/étnica/de gênero).

- Discursos políticos, científicos e populares, segundo os quais indivíduos ou grupos interpretam e constroem suas próprias posiçōes e as de outros na sociedade.

- Estruturas legais e institucionais (por exemplo, lei de apartheid, leis multiculturais ou contra a discriminação).

- Políticas (por exemplo, políticas racistas de migração, de integração ou compensatórias).
4. Joan Acker (2006) desenvolveu a expressão regime de desigualdade e com ela todo um programa de pesquisa dedicado a explorar as relações entre gênero, raça e classe dentro de organizações. Seu trabalho é uma contribuição poderosa às discussōes sobre interseccionalidade, mas não trata da dimensão transnacional ou histórica da desigualdade. Portanto, a despeito das semelhanças semânticas, a expressão regime de desigualdade usada aqui tem pouco em comum com o programa de pesquisa de Acker. 
- Modelos de convivência cotidiana, contemplando formas de convivência mais segregadoras ou mais integradoras (cf. Gilroy, 2005).

Com base nessa definição de regime de desigualdade, exploro, na seção a seguir, as desigualdades que afetam os afrodescendentes na América Latina.

\section{Afrodescendentes na América Latina}

De uma perspectiva socioeconômica, política e cultural, os afrodescendentes representam uma população muito heterogênea. Por conseguinte, essa categoria demográfica inclui diferentes grupos, tais como comunidades da costa do Pacífico, na Colômbia, que se distinguem por formas de vida e tradiçôes particulares transmitidas ao longo de gerações, e uma classe média emergente em São Paulo que está bem integrada ao mercado de trabalho dessa cidade global.

Essa heterogeneidade também se reflete nas estatísticas demográficas. De dezenove países latino-americanos, doze deles incluíram, nos censos realizados em torno do ano de 2010, questões explícitas referentes à cor/ raça ou à identidade de grupo afrodescendente. As questões correspondentes variam consideravelmente de país para país. Enquanto em países como o Brasil ou El Salvador se pergunta pela cor ou raça (preto, branco, pardo etc.), em países como Argentina, que introduziu o quesito correspondente no Censo de 2010, interessa a ascendência. Isto é, pergunta-se se as pessoas do domicílio são afrodescendentes ou têm antepassados africanos ou afrodescendentes. Em outros casos, como Honduras, pergunta-se pela "identidade étnica” de acordo com a pertença a grupos como "Garífuna” e "Negro Inglês". Existe, ainda, como mostra o caso do Equador, o esforço de combinar classificações relativas à ascendência, à pertença étnica e à cor e raça, de sorte que o entrevistado pode autoclassificar-se como: indígena, afro-equatoriano/afrodescendente, negro, mulato, Montubio, mestiço, branco ou outro (cf. Cruces et al., 2012).

As discrepâncias categoriais entre o censo nos vários países da América Latina e do Caribe tornam difícil determinar com precisão o tamanho da população afrodescendente. De uma perspectiva histórica, pode ser observada uma diminuição da participação dos afrodescendentes na população total da América Latina.

Contudo, pesquisas nacionais recentes registram um aumento da porcentagem das populações afrodescendentes em alguns países. Essa tendência 
está muito provavelmente relacionada com o novo quadro político e reflete fenômenos como a emergência de um novo movimento negro e a expansão de direitos e políticas para os afrodescendentes que reforçam a disposição de um maior número de pessoas de se autorreconhecer como afrodescendente.

De acordo com estimativas da Cepal, a Comissão Econômica das Nações Unidas para a América Latina, os afrodescendentes podem chegar até cerca de 30\% da população da América Latina e do Caribe - ou 150 milhões de um total de 500 milhões, em números arredondados. Geograficamente, a população afrodescendente está concentrada no Brasil (50\%), Colômbia (20\%), Venezuela (10\%) e Caribe (16\%) (cf. Antón et al., 2009). Em média, os afrodescendentes - em especial as mulheres - têm uma expectativa de vida menor, vivem em piores condições, têm níveis mais baixos de educação formal e acesso mais limitado aos serviços públicos do que a população latino-americana como um todo.

Se os afrodescendentes na América Latina conformam um grupo tão heterogêneo e seus dados demográficos apresentam disparidades tão grandes, quais são as razões para agrupar essa população em uma única categoria?

Pode-se supor que, juntamente com uma história comum, existem estruturas semelhantes de desigualdade e um quadro jurídico e político análogo que aproximam os afrodescendentes na América Latina para além das fronteiras nacionais. Assim, tratar os afrodescendentes como um grupo que transcende as fronteiras nacionais destaca uma clara referência transnacional no que diz respeito às estruturas de desigualdade, geralmente negligenciada nas abordagens centradas no Estado-nação 5 .

As desigualdades entre os afrodescendentes e os latino-americanos brancos não podem ser explicadas somente pelas desvantagens acumuladas durante o período da escravidão. As pesquisas recentes têm logrado mostrar que, em vários países latino-americanos, alguém ser categorizado como não branco ainda se correlaciona diretamente com uma posição socioeconômica desvantajosa e com menores chances de mobilidade ascendente. Consequentemente, se os fatores comuns que contribuem para a desigualdade, como sexo, região, renda e educação escolar dos pais, são estatisticamente controlados, as diferenças remanescentes entre as posições sociais numa sociedade dada só podem ser explicadas pelas adscrições raciais (cf. Costa, 2006).

A Tabela 2 apresenta indicadores de pobreza para Brasil, Equador e Nicarágua, como um exemplo das desigualdades que existem (e persistem até) hoje.
5. Historicamente, os afrodescendentes tiveram uma trajetória comum ("geteilte Geschichte") na América Latina no duplo sentido do termo, tal como entendido por Conrad e Randeria (2002): uma história partilhada e dividida. Isso implica que existe uma experiência partilhada como parte da história da diáspora africana na América Latina, mas que essa experiência é separada pelas narrativas das histórias nacionais. 
TABELA 2

População abaixo da linha de pobreza e indigência por grupo étnico (em porcentagem)

\begin{tabular}{l|l|l|l|l}
\hline \hline PAís & GruPo ÉTNICO & INDIGENTE & POBRE NĀO INDIGENTE & POBREZA TOTAL \\
\hline \hline \multirow{3}{*}{ Brasil (2006) } & Afrodescendente & 13,0 & 31,9 & 44,8 \\
& Branco & 5,0 & 16,8 & 21,7 \\
& Total & 9,0 & 24,3 & 33,2 \\
\hline \multirow{3}{*}{ Equador (2006) } & Afrodescendente & 22,4 & 36,2 & 58,5 \\
& Branco/mestiço & 14,2 & 25,4 & 39,6 \\
& Total & 15,4 & 26,1 & 41,5 \\
\hline \multirow{3}{*}{ Nicarágua (2001) } & Afrodescendente & 56,3 & 31,3 & 87,6 \\
& Branco/mestiço & 41,2 & 27,0 & 68,2 \\
& Total & 42,3 & 26,8 & 69,1 \\
\hline \hline
\end{tabular}

Fonte: Antón et al. (2009).

\section{Afrodescendentes na América Latina: regimes de desigualdade}

Ao longo da história, podem ser identificados ao menos quatro regimes de desigualdades relacionados com os afrodescendentes na América Latina: escravidão, nacionalismo racista, nacionalismo mestiço, regime compensatório.

No curso do tráfico negreiro entre os séculos XVI e XIX, aproximadamente 10 milhões de africanos escravizados foram levados para as colônias europeias na América Latina e no Caribe para trabalhar nas plantações, nas minas, no serviço doméstico etc. A escravidão seguiu padrões e modelos diferentes nos diversos países da América Latina, bem como em diferentes regiões dentro de um país. A nova historiografia sobre a escravidão também demonstrou a importância considerável de decisões individuais e negociações interpessoais para moldar as relações entre senhores e escravos (cf. Reis, 1999, p. 437). No entanto, a divisão racial das sociedades prevaleceu durante a escravidão, demarcando dois grupos com diferentes estatutos políticos, jurídicos e sociais: pessoas escravizadas, em geral negros, e homens livres, em geral

6. Como mostra acuradamente Góngora-Mera (2012) em sua genealogia das articulações históricas entre raça e lei na América Latina, a lei funcionou desde o começo da colonização como uma ligação transregional para sustentar a supremacia branca nas colônias. brancos. Portanto, as sociedades escravistas na América Latina funcionavam de certo modo como uma sociedade de castas: a mobilidade social de escravo para homem livre implicava complexas negociaçōes e só existia em casos excepcionais (cf. Cardoso, 1962). Categorizaçôes sociais como branco ou negro, que definiam a posição social em sociedades escravistas, eram construídas além das fronteiras nacionais, no interior de interpenetraçōes entre colonialismo, tráfico de escravos e fluxos de comércio transatlânticos ${ }^{6}$. 
A consolidação dos Estados-nação que se seguiu ao fim da escravidão refletiu a influência do racismo científico que vinha da Europa, determinando décadas de vigência de um modelo nacionalista racista.

Com efeito, os pais fundadores dos Estados modernos na América Latina empreenderam esforços deliberados para "europeizar" suas sociedades por meio do controle da imigração e da proibição de práticas religiosas e culturais afro-latino-americanas, buscando obliterar o legado africano. Como afirma o historiador Andrews, esse período foi dominado por uma "guerra contra a negritude":

Em todos os países da região, escritores, políticos e planejadores estatais lutaram com o problema da herança racial da América Latina. Como crentes firmes no determinismo racial, eles não tinham dúvida de que as trajetórias históricas de indivíduos, nações e povos eram irrevogavelmente determinadas por sua ascendência "racial". [...] A resposta latino-americana a esse dilema foi um esforço ousado, visionário e em última instância quixotesco de transformar-se de sociedades racialmente mistas, predominantemente não brancas, em repúblicas brancas habitadas por caucasianos e seus descendentes (Andrews, 2004, p. 118).

Essa "guerra contra a negritude" teve profundas consequências tanto no nível jurídico como no de diferentes políticas: de acordo com os dogmas do racismo científico, diferentes governos de Estados latino-americanos independentes adotaram leis de imigração restritivas e desenvolveram programas "higienistas", bem como medidas destinadas a controlar o casamento “inter-racial” (cf. Andrews, 2004; Góngora-Mera, 2012, pp. 20ss.).

$\mathrm{Na}$ década de 1930, a glorificação da mistura biológica e cultural expressa ilustrativamente no conceito de mestiçagem suplantou o nacionalismo racista. Os discursos nacionais dominantes passaram a ser marcados por uma ideologia nacional que celebrava a convivência pacífica de todos os grupos e tradições de origem europeia, indígena e africana. $\mathrm{O}$ surgimento coetâneo do relativismo cultural na antropologia cultural internacional - e especialmente o trabalho de Franz Boas - teve grande influência nos discursos sobre a mestiçagem na América Latina. Alguns dos inventores mais importantes da ideologia da mestiçagem foram diretamente influenciados por Boas, entre eles Gilberto Freyre, no Brasil, e Fernando Ortíz, em Cuba (cf. Hofbauer, 2006).

A posição dos afrodescendentes no discurso da mestiçagem é ambivalente. Por um lado, esse discurso celebra o papel dos afrodescendentes como aliados dos colonizadores europeus, no âmbito do processo de "civilização" dos tró- 
picos, bem como a importância deles para o desenvolvimento de identidades nacionais mestiças. Ao mesmo tempo, esse discurso de inclusão significa a renúncia a uma identidade afrodescendente. Assim, o que é relevante para a mestiçagem não é mais a ascendência africana dos afrodescendentes, mas sua integração nas nações brasileira, cubana ou colombiana, que representam, de acordo com o discurso da mestiçagem, um prolongamento da civilização europeia nos trópicos (cf. Costa, 2010a).

Se o discurso sobre a mestiçagem funcionou como um programa político para assimilar e subordinar diferenças culturais, ele também serviu como modelo de convivência. Assim, estudos etnográficos no Equador (cf. Walsh, 2009), no Brasil (cf. Almeida, 2000; Sansone, 2003) e na Colômbia (cf. Wade, 2005) demonstraram como esse discurso funciona como uma construção multifacetada que conecta diferentes padrões de coexistência intercultural. Os achados de Peter Wade, baseados em seus estudos de música na Colômbia, religiosidade popular na Venezuela e cristianismo popular no Brasil, são particularmente valiosos a esse respeito. Conforme Wade, uma vez que sujeitos individuais e coletivos reinterpretam e redefinem o discurso ideológico em sua vida cotidiana, a mestiçagem é predominantemente uma experiência vivida:

Tudo isso nos leva a uma visão da mestiçagem que é bastante diferente da imagem usual dos processos nacionalistas que se empenham em criar uma identidade homogênea que acaba apagando a negritude e o indigenismo a fim de terminar com um mestiço branqueado que representa a fusão irrecuperável de três origens raciais. Leva, em vez disso, à imagem da mestiçagem como a construção de um mosaico, que pode ser encarnado em uma única pessoa ou dentro de um complexo de práticas religiosas, bem como dentro da nação. Esse mosaico é bastante diferente do mosaico do que poderia ser chamado de multiculturalismo oficial, em que cada "cultura" é confinada dentro de certos limites institucionais. O mosaico da mestiçagem permite a permanente recombinação de elementos em pessoas e práticas (Idem, p. 252).

Como ideologia, a mestiçagem ainda tem ressonância política. Contudo, desde a década de 1990, ela tem sido desafiada por um quadro internacional de mudança e pela presença de novos atores de protesto no cenário nacional e internacional. Esses novos desenvolvimentos explicam a emergência de um novo padrão de desigualdade que eu chamo de regime compensatório.

Já durante a década de 1980, podia-se observar a maneira pela qual organizaçōes multilaterais mudaram sua agenda de sorte a perceber a "diversidade 
cultural" como um recurso para o desenvolvimento e não mais como um problema. De acordo com Kymlicka, tais “odisseias multiculturais” mudaram radicalmente a lógica de funcionamento das organizações multilaterais que havia predominado desde o fim da Segunda Guerra Mundial:

[...] Os arquitetos da ONU e das organizações regionais do pós-guerra assumiram que os direitos das minorias não apenas eram desnecessários para a criação de uma nova ordem internacional viável, como eram na verdade desestabilizadores de tal ordem. Hoje, porém, como é amplamente reconhecido, a acomodação da diversidade étnica é não apenas coerente com a manutenção de uma ordem internacional legítima mas de fato uma precondição para ela (Kymlicka, 2007, p. 45).

O discurso sobre o multiculturalismo também entrou na retórica dos governos nacionais e locais na América Latina, uma retórica que agora celebra publicamente a identidade cultural de indígenas e afrodescendentes.

O papel dos diferentes movimentos culturais e sociais não pode ser subestimado nesse contexto. Desde a década de 1990, os movimentos negros e afro-latino-americanos passaram por um importante processo de transnacionalização e diferenciação interna. Culturalmente, isso resultou na rápida disseminação da chamada Cultura Negra no espaço imaginado do Atlântico Negro (cf. Gilroy, 1993, 2010), que na América Latina inclui manifestaçôes como reggae, capoeira, hip-hop etc.

Politicamente, a Conferência Mundial das Nações Unidas contra o Racismo de 2001, realizada em Durban, África do Sul, representa um divisor de águas. As reuniōes preparatórias e aquelas que se seguiram à conferência tornaram possível a fundação de inúmeras organizações afro-latino-americanas, bem como o estabelecimento de importantes redes antirracistas transnacionais. Além disso, a mobilização de mulheres negras e outras minorias internas assegura uma pluralização dos movimentos negros e afro-latino-americanos ao trazer a questão da diversidade de temas negros para o primeiro plano (cf. Costa, 2006, 2011). Esses novos desenvolvimentos começaram a se refletir em políticas sociais e novos marcos regulatórios que afetam a população afrodescendente em diferentes países ${ }^{7}$.

A seguir, apresento um rápido resumo dos principais instrumentos jurídicos e das políticas sociais que buscam atender os interesses da população afrodescendente. Distingo três gerações de medidas.

\footnotetext{
7. Em referência a políticas que consolidam e ampliam os direitos da população afrodescendente, seria importante também considerar as contribuiçōes de atores não estatais e de agências de cooperação internacionais. Esse campo inclui numerosas ONGS que fornecem informação jurídica e coordenam projetos sociais, bem como instituiçôes multilaterais e internacionais como, por exemplo, o Banco Mundial, que financia programas especiais de apoio a afro-equatorianos, e a Fundação Ford, que é o mais importante apoiador financeiro da articulação política para afro-brasileiros (cf. Telles, 2003). Neste texto, não me refiro a esses desenvolvimentos, limitando-me a uma visão geral de medidas estatais relativas à implementaçẫo de direitos políticos, sociais e culturais.
} 


\section{Proteção contra discriminação}

Em escala internacional, o direito à proteção contra discriminação remonta à Declaração Universal dos Direitos Humanos adotada pela ONU em 1948. A Convenção da ONU sobre a Eliminação de Todas as Formas de Discriminação Racial (Icerd), de 1969, que até 1990 tinha sido assinada por todos os países latino-americanos, é igualmente relevante nesse contexto. Em 1979, foi estabelecida a Corte Interamericana de Direitos Humanos da Organização dos Estados Americanos (OEA). Em 2005, foi criada, no âmbito da Comissão Interamericana de Direitos Humanos, a "Relatoria de direitos de afrodescendentes e contra a discriminação racial", visando reforçar o respeito aos direitos dos afrodescendentes nas Américas (cf. Olmos Giupponi, 2010; Costa e Gonçalves, 2011).

Os países latino-americanos, em sua maioria, integraram essas convenções e instrumentos de direitos humanos internacionais em suas constituições. Pode-se afirmar que a discriminação com base na cor ou na identidade étnica está sujeita a sanções legais em toda a América Latina. Em termos de política, muitos países criaram centros de informação, tribunais especializados e postos de assessoria jurídica que trabalham exclusivamente com casos de discriminação contra afrodescendentes (cf. Machado et al., 2008). A eficácia dessas medidas varia de país para país, dependendo de fatores como o grau de consolidação do sistema jurídico, o poder político dos movimentos antirracistas etc. (cf. Costa, 2011).

\section{Proteção aos direitos culturais}

A segunda geração de instrumentos jurídicos é associada à já mencionada "odisseia multicultural". Nesse contexto, a Convenção 169 da Organização Internacional do Trabalho (ОIT), promulgada em 1989, não pode ser subestimada. Quase todos os países da América Latina ratificaram a convenção que estendeu substancialmente os direitos de povos indígenas. $\mathrm{O}$ termo "povos" é importante, pois permite a referência a direitos coletivos como reivindicaçõos de terras e preservação de línguas. Essa é a razão pela qual a Convenção se tornou um argumento central de legitimação para promover as demandas dos movimentos étnicos na América Latina para além do que se entende estritamente como povos indígenas, como as comunidades de afrodescendentes. Muitas dessas demandas também foram contempladas nas reformas constitucionais mais recentes. 
Em países como Brasil, Colômbia, Nicarágua e Honduras, a efetivação desses direitos, na forma de políticas concretas, é especialmente pronunciada. A atribuição de títulos de propriedade e a introdução de programas sociais são medidas importantes que incentivam o fortalecimento das chamadas comunidades tradicionais e afrodescendentes, como no caso dos quilombos, no Brasil, e dos palenques, na Colômbia. Igualmente importantes são os programas que promovem a "educação étnica", incluindo medidas como financiamento de pesquisa sobre a história das comunidades afro-latino-americanas e a incorporação da história da Diáspora Africana em currículos escolares (cf. Antón et al., 2009; Olmos Giupponi, 2010; Costa, 2012).

\section{Promoção da igualdade de oportunidades ("discriminação positiva")}

A terceira geração de instrumentos jurídicos e de políticas que dizem respeito à população afrodescendente pode ser remontada às mobilizações locais no âmbito da preparação para a conferência da ONU de 2001 em Durban. A declaração final da conferência e seu plano de ação pedem explicitamente que os Estados garantam o acesso adequado dos afrodescendentes à educação, às novas tecnologias e aos sistemas legais. Brasil e Colômbia, em particular, lançaram tentativas de implementar legal e institucionalmente os objetivos declarados da conferência. Por exemplo, em 2003, o Brasil estabeleceu uma secretaria federal, a Seppir, com status de ministério para a "promoção da igualdade racial" (cf. Costa, 2010b). Na Colômbia, mudanças constitucionais que criam condições legais para apoiar afro-colombianos no mercado de trabalho e no sistema de educação estão em negociação (cf. Góngora-Mera, 2012).

Não é possível determinar com precisão como esses novos marcos legais e políticos afetam as estruturas de desigualdade. O que está claro, no entanto, é que os preconceitos étnicos, raciais e de gênero que moldam as estruturas de desigualdade na América Latina não desaparecem imediatamente após a implementação dessas medidas. Deve-se supor, então, que diferentes mecanismos de estratificação coexistem no regime de desigualdade compensatório $^{8}$. Eles são, em linhas gerais, os seguintes:

a) Estruturas de classe que regem o acesso a bens e posições desejadas na sociedade de acordo com critérios da economia de mercado.

b) Adscriçỗes raciais, étnicas e de gênero. De acordo com esse mecanismo
8. De acordo com minha definição de regimes de desigualdade apresentada acima, eu deveria fornecer uma descriçăo das formas de convivência características dos regimes compensatórios. Todavia, isso exigiria uma observação etnográfica de diferentes experiências cotidianas em uma variedade de países, extrapolando em muito os limites desse artigo e de seu autor. 
de estratificação, o acesso a bens e a posições é definido por preconceitos e formas diversas de discriminação.

c) Grupos-alvo: pertencer a um grupo definido, que é alvo de certa política, determina, nesse caso, acesso diferenciado a recursos.

Como mencionado acima, meu principal objetivo neste artigo é apresentar as desigualdades sociais como um produto de interdependências entre diferentes categorizações sociais e entre diferentes entrelaçamentos transregionais. Para esse fim, destaco no quadro a seguir as principais interdependências e entrelaçamentos encontrados nos quatro regimes de desigualdade que historicamente abrangeram os afrodescendentes na América Latina.

QUADRO 2

Afrodescendentes na América Latina: regimes de desigualdade

\begin{tabular}{|c|c|c|c|}
\hline & Período & $\begin{array}{l}\text { PRINCIPAL LÓGICA DE ESTRATIFICAÇĀO/ } \\
\text { REDISTRIBUIÇĀO }\end{array}$ & ENTRELAÇAMENTOS TRANSREGIONAIS \\
\hline Escravidão & Até o século XIX & Casta & $\begin{array}{l}\text { Tráfico de escravos, comércio triangular } \\
\text { (Europa, África, Américas) }\end{array}$ \\
\hline Nacionalismo racista & $\begin{array}{l}\text { Das abolições a aproxi- } \\
\text { madamente } 1930\end{array}$ & Adscrição racial & $\begin{array}{l}\text { Intercâmbio internacional dentro do } \\
\text { racismo científico (Europa, Américas) }\end{array}$ \\
\hline Nacionalismo mestiço & $1930-1990$ & Classe, adscrição racial, de gênero & $\begin{array}{l}\text { Circulação de conceitos culturalistas } \\
\text { (Américas) }\end{array}$ \\
\hline Regime compensatório & Desde 1990 & $\begin{array}{l}\text { Classe, adscrição racial, de gênero, } \\
\text { população-alvo }\end{array}$ & $\begin{array}{l}\text { Alianças antirracistas transnacionais } \\
\text { (Atlântico Negro), organizações mul- } \\
\text { tilaterais }\end{array}$ \\
\hline
\end{tabular}

\section{Conclusões}

O conceito de desigualdades entrelaçadas, cunhado neste texto, busca reconstruir os vínculos entre desigualdades sociais, interdependências globais e interpenetrações entre distintas categorizações sociais. Consequentemente, desigualdades sociais são definidas aqui como assimetrias entre as posições de certos indivíduos ou grupos de indivíduos em um contexto relacionalmente (e não espacialmente) determinado. Isso diz respeito a posições econômicas 
(definidas por renda, acesso a recursos etc.), assim como a prerrogativas políticas e legais (direitos, poder político etc.). Para compreender as articulações das quais surgem posiçôes desiguais, é necessário ter unidades relacionais de análise que sejam dinamicamente definidas no próprio processo de investigação. De modo semelhante, a interação de categorizaçōes sociais (gênero, raça, classe, etnia etc.) não pode ser articulada ex-ante em uma fórmula teórica; só pode ser estudada no respectivo contexto específico.

Ao propor o conceito de regimes de desigualdade, tentei cunhar uma unidade dinâmica de análise que permite captar as interdependências entre categorizaçôes sociais e entre diferentes regiōes do mundo. Além disso, o rastreamento de diferentes regimes de desigualdade inter-relacionados ao longo do tempo permite contemplar a construção histórica das desigualdades.

$\mathrm{Na}$ segunda metade do artigo, examinei regimes de desigualdade que historicamente abrangeram os afrodescendentes na América Latina: escravidão, nacionalismo racista, nacionalismo mestiço e regime compensatório. Cada regime é moldado por um conjunto diferente de entrelaçamentos globais.

Em cada um desses regimes, uma interação de categorizações sociais específica ocupa o primeiro plano: durante a escravidão, o status de ser escravizado prevalece, enquanto outras atribuiçōes se tornaram secundárias. Hoje, em contraste, a posição dos afrodescendentes nas estruturas de desigualdade depende de uma combinação complexa de diversas categorias: classificações etnorraciais (que não podem ser reduzidas à dualidade preto-branco), classe, sexo, grupos-alvo de direitos e políticas etc.

Dependendo de qual nível do regime de desigualdade é levado em conta, essas posiçôes variam: ser categorizado como "negro", por exemplo, pode ser vantajoso em relação ao acesso a algumas políticas - por exemplo, a política de cotas. Todavia, em outros níveis do regime de desigualdade - como discurso, padrões de convivência -, ser classificado como não branco está associado, via de regra, a uma posição subordinada.

Referências Bibliográficas

ACKER, Joan. (2006), "Inequality regimes: gender, class, and race in organizations". Gender \& Society, 20 (4): 441-464.

AlmeIDA, Miguel V. (2000), Um mar da cor da terra: raça, cultura e política da identidade. Oieieras, Celta.

Andrews, George Reid. (2004), Afro-latin America, 1800-2000. Oxford, Oxford University Press. 
AnTón, Jhon et al. (2009), Afrodescendientes en America Latina y el Caribe: del reconocimiento estadístico a la realización de derechos. Santiago de Chile, Cepal.

Bastide, Roger \& Fernandes, Florestan. (1959), Negros e brancos em São Paulo. São Paulo, Cia. Editora Nacional.

Berger, Peter A. \& Weiß, A. (orgs.). (2008), Transnationalisierung sozialer Ungleichheiten. Wiesbaden, vs.

Cardoso, Fernando H. (1962), Capitalismo e escravidão no Brasil meridional: o negro na sociedade escravocrata do Rio Grande do Sul. São Paulo, Difusão Europeia do Livro.

Cardoso, Fernando H. \& Falleto, Enzo. (1969), Dependencia y desarollo en América Latina. México/Buenos Aires.

Cardoso, Fernando H. \& Ianni, Octávio. (1960), Cor e mobilidade social em Florianópolis: aspectos das relaçôes entre negros e brancos numa comunidade do Brasil meridional. São Paulo, Cia. Editora Nacional.

Conrad, Sebastian \& Randeria, Shalini. (2002), "Einleitung. Geteilte Geschichten. Europa in einer postkolonialen Welt". In: (orgs.). Jenseits des Eurozentrismus. Postkoloniale Perspektiven in den Geschichts- und Kulturwissenschaften. Frankfurt a.M., Campus, pp. 9-49.

Costa, Sérgio. (2006), Dois Atlânticos. Teoria social, antirracismo, cosmopolitismo. Belo Horizonte, Editora UFMG.

(2010a), "Da sociologia do racismo às políticas antirracistas: nexos difíceis". In: D'Incao, M. A. \& Martins, H. (orgs.). Democracia, crise e reforma. Estudos sobre a era Fernando Henrique Cardoso. São Paulo, Paz \& Terra, pp. 245-268.

. (2010b), "Au-delà du métissage: antiracisme et diversité culturelle sous les deux gouvernements Lula”. Problèmes d'Amérique Latine, 78: 91-112.

(2011), "Perspectivas y políticas sobre racismo y afrodescendencia en América Latina y el Caribe”. In: Hopenhayn, M. \& Sojo, A. (orgs.). Sentido de pertenencia en sociedades fragmentadas: América Latina en una perspectiva global. Santiago de Chile, Cepal, pp. 173-188.

. (2012), "Freezing differences: politics, law, and the invention of cultural diversity in Latin America”. In: Araujo, Kathya \& Mascareno, Aldo (orgs.). Legitimization in world society. Farnham, Ashgate, pp. 139-156.

Costa, Sérgio \& Gonçalves, Guilherme L. (2011), "Human rights as collective entitlement? Afro-descendants in Latin America and the Caribbean”. Journal for Human Rights/Zeitschrift für Menschenrechte, 2: 52-71.

CRuCES, Guillermo et al. (2012), "Visibilidad estadística: datos sobre población afrodescendiente en censos y encuestas de hogares de América Latina”. Panamá, Programa de las Naciones Unidas para el Desarrollo/Ministerio de Asuntos Exteriores de Noruega. 
Degler, Carl N. (1976), Nem preto nem branco: escravidão e relaçôes raciais no Brasil e nos Estados Unidos. $1^{\text {a }}$ edição 1971. Rio de Janeiro, Labor.

Fernandes, Florestan. (1965), A integração do negro na sociedade de classes. São Paulo, Dominus, 2 vols.

Gilroy, Paul. (1993), The black Atlantic. Cambridge, Harvard University Press. . (2005), Postcolonial melancholia. Nova York, Columbia University Press. (2010), Darker than blue: on the moral economies of black Atlantic culture. Cambridge, MA, Harvard University Press.

Góngora-Mera, Manuel E. (2012), Transnational articulations of law and race in Latin America: a legal genealogy of inequality. Berlim, Working Paper desiguaLdades.net, n. 18.

Guimarães, Antonio S. (2002), Classes, raças, democracia. São Paulo, Fusp/Editora 34. Hanchard, Michael. (1994), Orpheus and the power. Princeton, Princeton University Press.

HarRIS, Marvis. (1956), Town and country in Brazil. Nova York, Columbia University Press.

HoffBauer, Andréas. (2006), Uma história de "branqueamento" ou o "negro" em questão. São Paulo, Editora da Unesp.

Ianni, Octávio. (1966), Raças e classes sociais no Brasil. Rio de Janeiro, Civilização Brasileira.

KorZENIEWICZ, Roberto Patricio. (2011), Inequality: on some of the implications of a world-historical perspective. Berlim, Working Paper Desigualdades.net, n. 3.

Korzeniewicz, Roberto Patricio \& Moran, Timothy Patrick. (2008), "Rethinking inequality: a world-historical perspective". Disponível em <http://gbif.ch/repository/ $\mathrm{default} /$ content/sites/inequality08/files/shared/documents/papers/korzeniewich. pdf>, consultado em 30/8/2011.

. (2009), Unveiling inequality: a world-historical perspective. Nova York, Russell Sage Foundation.

Kymlicka, Will. (2007), Multicultural Odysseys. Oxford, Oxford University Press.

Lovell, Peggy A. (1995), "Raça e gênero no Brasil". Lua nova, 35, pp. 39-71.

MACHADO, Marta et al. (2008), "The public sphere and the anti-racism legal protections in Brazil". Social Science Research Network, disponível em <http://www.ssrn. com/>, consultado em 13/4/2012.

Nobles, Melissa. (2000), Shades of citizenship: race and the census in modern politics. Stanford, Stanford University Press.

Olmos Giupponi, Belén M. (2010), "La protección de las comunidades afrodescendientes en el sistema interamericano: reflexiones a la luz del caso de las comunidades Jiguamiadó y de Curbaradó”. Revista Eletrónica Iberoamerica, 4 (2): 61-97. 
Pierson, Donald. (1942), Negroes in Brazil. Chicago, University of Chicago Press.

PrIEs, Ludger. (2008), "Transnationalisierung und soziale Ungleichheit. Konzeptuelle Überlegungen und empirische Befunde aus der Migrationsforschung”. In: BERGER, Peter A. \& Weiß, A. (orgs.). Transnationalisierung sozialer Ungleichheiten. Wiesbaden, vs, pp. 41-64.

ReIS, José J. (1999), "Slaves as agents of history: a noten on the new historiography of slavery in Brazil”. Ciência e Cultura, 51 (5, 6): 437-445.

SANSONE, Livio. (2003), Blackness without ethnicity: constructing race in Brazil. Londres, Palgrave Macmillan.

STEWART, Frances. (2000), "Crisis prevention: tackling horizontal inequalities". Oxford Development Studies, 28 (3): 245-262. (2010), "Por qué persisten las desigualdades de grupo? Las trampas de la desigualdad horizontal”. In: JimÉnez, Félix (org.). Teoría económica y desigualdad social: exclusión, desigualdady democracia. Homenaje a Adolfo Figueroa. Lima, Fondo Editorial de la PUC - Peru, pp. 269-298.

Stewart, Frances, Brown, Graham \& Mancini, Luca. (2005), "Why horizontal inequalities matter: some implications for measurement". CRISE Working Paper, n. 19, University of Oxford. Disponível em <http://www.crise.ox.ac.uk/pubs/ workingpaper19.pdf>.

Telles, Edward Eric. (2003), Racismo à brasileira: uma nova perspectiva sociológica. Rio de Janeiro, Relume Dumará.

THORP, Rosemary \& PAREDEs, Maritza. (2010), Ethnicity and the persistence of inequality: the case of Peru. Houndmills, Palgrave Macmillan.

WADE, Peter. (2005), "Rethinking mestizaje: Ideology and lived experience". Journal of Latin American Studies, 37 (2): 239-257.

WAGLeY, Charles (org.). (1952), Race and class in rural Brazil. Paris, Unesco.

Walsh, Catherine. (2009), Interculturalidad, estado, sociedad: luchas (de) coloniales de nuestra época. Quito, Universidad Andina Simón Bolivar.

Weiß, Anja. (2005), "The transnationalization of social inequality: conceptualising social positions on a world scale”. Current Sociology, 53 (4): 707-728. 


\section{Resumo}

Desigualdades, interdependências e afrodescendentes na América Latina

Desigualdades sociais foram tradicionalmente investigadas no âmbito do Estado-nação, privilegiando-se as diferenças de classe e a perspectiva sincrônica. Isto é: ainda que a investigação especializada, sobretudo na América Latina, venha se dedicando já há algumas décadas a estudar os nexos entre classe e outras formas de classificação social (raça, gênero etc.), só muito recentemente registram-se avanços substantivos na investigação sobre os processos históricos e os nexos globais que configuram as desigualdades observadas num país determinado. O presente artigo, em sua primeira parte, oferece um panorama desses avanços, traçando um marco analítico para o estudo de desigualdades sociais a partir de interdependências históricas, geográficas e relativas às diferentes formas de classificação social. A segunda parte aplica as referências analíticas desenvolvidas ao estudo das desigualdades que afetam a população afrodescendente na América Latina. Palavras-chave: Desigualdades sociais; Interdependências globais; Afrodescendentes.

\section{Abstract}

Social inequalities, interdependencies and Afro-descendants in Latin America

Social inequalities have conventionally been investigated as synchronous processes occurring within the contours of national borders and connected to the concept of class. As a consequence established scholarship, especially in Latin America, has given little attention to the historical dimensions and global entanglements between class and other social classifications that have shaped existing inequalities. A number of recent contributions have attempted to correct these analytical shortfalls from a variety of perspectives. In order to overcome methodological nationalism, a first group of contributions has focused on the interconnections between national and global structures of inequality, showing how inequalities correspond to entanglements between social processes at different geographical levels: local, national, global. A second group of contributions has investigated the relationship between different axes of stratification, focusing on how social inequalities emerge at the intersections between different social ascriptions, particularly those of race, class, gender and ethnicity. This paper presents a brief survey of the debates in both fields as well as a set of resources for overcoming the current deficits in the research on interdependent inequalities. In order to illustrate how some of these resources operate analytically, the second half of the paper discusses the case of social inequalities affecting Afro-descendants in Latin America. Keywords: Social inequalities; Global interdependencies; Afro-descendents.
Texto recebido em 1/8/2012 e aprovado em 6/8/2012.

Sérgio Costa é professor titular de sociologia do Instituto de Estudos Latino-Americanos e do Instituto de Sociologia da Freie Universität Berlin, Alemanha. E-mail: <sergio.costa@ fu-berlin.des. 